\title{
Localización y evidencias geológicas enfocados en la determinación del yacimiento tipo IOCG Cerro Colorado Chico, Ancash-Perú
}

\author{
Localization and evidences focused in the determination to Cerro Colorado \\ IOCG deposit, Ancash-Peru
}

\author{
Alberto Torres Guerra ${ }^{1}$, John Cerrón Sarcco ${ }^{2}$, Deivi López Varillas ${ }^{3}$ \\ Recibido: Enero 2020 - Aprobado: Junio 2020 - Publicado: Junio 2020
}

\begin{abstract}
RESUMEN
Esta publicación es parte del proyecto: "Estudio del magmatismo Mesozoico y sus implicancias en la determinación de un modelo de exploración geológico estructural relacionado con la ocurrencia de Yacimientos tipo IOCG en la Cordillera de la costa y llanuras pre-andinas de los Andes Peruanos" por medio del convenio marco entre UNMSM e INGEMMET. La localización de las áreas prospectables fue usando imágenes Landsat 8 , eligiendo Cerro Colorado Chico por su accesibilidad. La geomorfología destaca por mostrar afloramientos de cerros aislados con fuerte oxidación y lomadas. En la etapa de campo se realizó la cartografía geológica de 5 zonas predefinidas y muestreo orientado. Se observó rocas intrusivas, volcánicas porfiríticas alteradas, brechas, vetas de cuarzos, arcillitas. La mineralización observada fue de calcopirita, covelita, gran cantidad de pirita, hematita, goethita, jarosita, etc. La alteración observada fue de fuerte silicificación, oxidación, sericitación, cloritización y piritización. Los resultados de los estudios petromineralógicos han determinado la presencia de rutilo, micas, argilización e incipiente carbonatación. La presencia de brechas silíceas sin mucha mineralización evidente, encontradas en la Zona C-2, podría indicar la presencia de un posible Quartz Pod, además de tener un gran halo hematita-goethita nos podría indicar alteración supérgena y zona de menor temperatura (por la presencia del halo de alteración cuarzo-hematita-sericita-clorita), dando la posible presencia de magnetita en profundidad. En base a estas evidencias se propone la existencia un yacimiento tipo IOCG en la Zona C-2, probablemente profundo que con mayores estudios enfocados se corroboraría esta hipótesis.
\end{abstract}

Palabras claves: IOCG; petromineralogía; alteración; teledetección; mapeo geológico.

\begin{abstract}
This publication is part of the project: "Study of Mesozoic magmatism and its implications in the determination of a geological-structural exploration model related to the occurrence of IOCG type deposits in the Cordillera de la Costa and pre-Andean plains of the Peruvian Andes" by means of the framework agreement between UNMSM and INGEMMET. The location of the prospective areas was using Landsat 8 images, choosing Cerro Colorado Chico for its accessibility. The geomorphology stands out for showing outcrops of isolated hills with strong oxidation and hills. In the field stage, the geological cartography of 5 predefined zones and oriented sampling was performed. Intrusive rocks, altered porphyritic volcanic rocks, gaps, quartz veins, clays were observed. The mineralization observed was chalcopyrite, covelite, large amount of pyrite, hematite, goethite, jarosite, etc. The alteration observed was of strong silicification, oxidation, sericitation, chloritization and piritization. The results of the petromineralogical studies have determined the presence of rutile, micas, argillization and incipient carbonation. The presence of siliceous gaps without much obvious mineralization, found in Zone C-2, could indicate the presence of a possible Quartz Pod, in addition to having a large hematite-goethite halo, it could indicate a supergenous alteration and a lower temperature zone (due to the presence of the halo of quartz-hematite-sericite-chlorite alteration), giving the possible presence of magnetite in depth. Based on these evidences, the existence of an IOCG Type deposit in Zone C-2 is proposed, probably deep that, with more focused studies, this hypothesis would be corroborated.
\end{abstract}

Keywords: IOCG; petrominerlagy; alteration; remote sensing; geological mapping.

\footnotetext{
${ }^{1}$ Docente Facultad de Ing. Geológica, Minera, Metalúrgica y Geográfica, Universidad Nacional Mayor de San Marcos. Lima, Perú. E-mail: albertorresg@hotmail.com ${ }^{2}$ Bachiller de Ing. Geológica. E. P. Ingeniería Geológica, Universidad Nacional Mayor de San Marcos. Lima, Perú. E-mail: jcerron@volcan.com.pe ${ }^{3}$ Bachiller de Ing. Geológica. E. P. Ingeniería Geológica, Universidad Nacional Mayor de San Marcos. Lima, Perú. E-mail: dlopez@volcan.com.pe
} 


\section{INTRODUCCIÓN}

Este trabajo es parte del proyecto denominado "Estudio del magmatismo Mesozoico y sus implicancias en la determinación de un modelo de exploración geológico estructural relacionado con la ocurrencia de Yacimientos tipo IOCG en la Cordillera de la costa y llanuras pre-andinas de los Andes Peruanos" que se realiza como parte del convenio entre UNMSM e INGEMMET. Partiendo de la utilización de herramientas de gabinete como la teledetección es que se definió 5 zonas prospectables, eligiendo una específica debido a su accesibilidad, ubicada cerca de $20 \mathrm{~km}$ al distrito de Paramonga, provincia de Huarmey, región Ancash. Toda esta zona ha sido blanco de estudio desde la década del 70 por empresas e instituciones como Cerro de Pasco Corporation, Newmont Mining, INGEMMET, entre otras. Se realizó el trabajo de campo con enfoque en tener una visión integral de la zona, tanto en características geomorfológicas, litológicas, estructurales, muestreo para análisis químico y estudios petromineralógicos. En este trabajo nos centramos a presentar las características geológicas y petromineralógicas de este yacimiento.

\subsection{Ubicación y accesibilidad}

El área de estudio Cerro Colorado Chico se encuentra ubicado a $230 \mathrm{~km}$ al Norte de la ciudad de Lima aproximadamente en el anexo de Pararin, distrito de Paramonga, provincia de Huarmey en la región Ancash. En coordenadas UTM (PSAD 56) para la parte central del proyecto son 180032
E - 8837902 N, ubicado en la carta 22-h. El acceso a la zona de estudio desde la ciudad de lima se realiza por la carretera Panamericana Norte, pasando Paramonga entre los Km. 229 y 231 (vía asfaltada) en los cuales se encuentran las huellas de acceso (Trochas). El tiempo total estimado de recorrido es en promedio de 3h 40' (Ver Figura 1).

\subsection{Geomorfología}

La zona de estudio (Cerro Colorado Chico) se encuentra en la planicie costera, al Oeste limita con la línea litoral y por el Este se nota la presencia de pequeños cerros los cuales corresponden a estribaciones andinas. La presencia de estas geoformas positivas se encuentra de manera aislada (ver Figura 2).

Los principales procesos de erosión - depósito corresponden a la dinámica marina y eólica la cual se manifiesta en la formación de playas y acantilados, y formación y migración de depósitos eólicos (dunas) respectivamente.

\subsection{Teledetección}

Como primer paso, a través del procesamiento e interpretación de imágenes satelitales Landsat 8, que abarcaron toda la costa peruana y con el apoyo del software ENVI 5.3, se determinó cinco áreas prospectivas que se sugirieron para su respectiva verificación de campo, de esta manera (ver Figura 3).

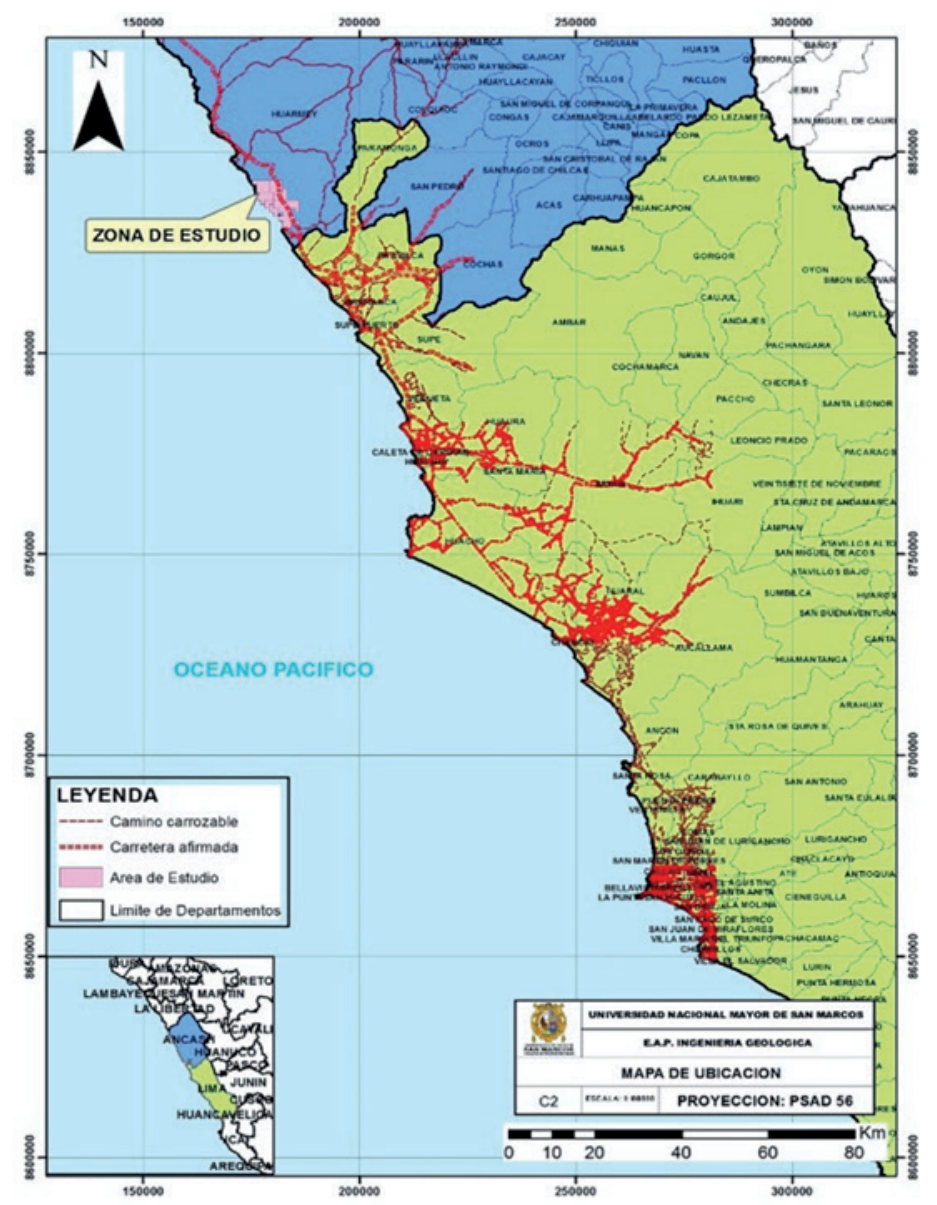

Figura 1. Mapa de Ubicación de Cerro Colorado Chico (Datos: INGEMMET-IGN) 
Se ha priorizado por su fácil accesibilidad y cercanía a la ciudad de Lima el área denominado "Cerro Colorado Chico" para su verificación de campo y posteriormente hacer los ajustes que fueran necesarios.

Las características espectrales del sensor Landsat 8, a través de sus subsistemas VNIR (Visible/Near Infrared), SWIR (Short-Wave Infrared), TIR (Thermal Infrared) nos permite principalmente determinar zonas de oxidación y minerales de alteración hidrotermal (arcillas), además delimitar estructuras geológicas (fallas, pliegues). Se ha realizado un procedimiento correctamente establecido desde la obtención de la imagen satelital, preprocesamiento, procesamiento hasta obtener los resultados. Para el procesamiento se realizó el uso de dos métodos, combinación de bandas y ratio de bandas, donde el segundo método nos dio una visión más nítida de la presencia de óxidos y arcillas.

Procesando mediante la combinación de bandas, donde al combinar las bandas blue, red, near infrared (NIR) y SWIR1 obtengo zonas con presencia de óxidos, y combinado las bandas red, near infrared (NIR), SWIR1 y SWIR2 obtengo zonas con presencia de arcillas (tonalidad verdosa, Figura 4).

Posteriormente se procesó con el método de ratio de bandas ("red/blue" para óxidos y "SWIR1/SWIR2" para arcillas) obteniendo zonas con presencia de óxidos (color rojo), arcillas (color verde) y óxidos-arcillas (color amarillo).

\subsection{Geología Regional}

El área de estudio se ubica en la Franja Costanera del Norte del Perú, compuesta por Grupo Casma (Guevara, C., 1980) del Cretáceo (130 - 105 Ma.) que se constituye como una secuencia volcánica submarina a subárea intercalados con estratos volcanoclasticos y sedimentarios (Cobbing, 1973), (Jacay, 2005) debido a un vulcanismo intermitente pertenecientes a una cuenca volcánica marginal durante el magmatismo del Arco Casma (Soler,
1990). Este Arco Casma estuvo ligado tectónicamente a una zona de subducción de bajo esfuerzo (Mamani et al., 2010) -donde el ángulo generado por el plano Benioff fue aproximadamente $60^{\circ}$ (Soler, 1990), (Soler \& Bonhomme, 1990)- estando caracterizado por series tholeiticas a calcoalcalinas (Cueva, E., Mamani, M., Rodríguez, R., s.f.) llegando inclusive a alcalinas (Mamani Huisa et al., 2012).

Durante finales del Cretácico sufrió plegamiento debido a su poca competencia (Cobbing, 1973) con una dirección Andina y Andino-Normal siendo pliegues abiertos con planos axiales subverticales con ejes subhorizontales según (Guevara, C., 1980) que cuando más cerca están al margen ascendente, pasan hacia fajas de deformación intensa (Faja Plegada Mesozoica) y a un grado de metamorfismo más alto durante la Orogenia Andina. Estos pliegues, a su vez, están cortadas por fallas de diversa magnitud.

Este Grupo fue intruído por rocas intrusivas subvolcánicas conformando Superunidades y cuerpos ácidos aislados con colores de oxidación según (Cobbing, 1973) del Batolito de la Costa perteneciente al segmento Lima (Cobbing \& Pitcher, 1979). En trabajos posteriores (J Jacay \& Sempéré, 2005) indican que estos cuerpos tienen geometría tabular con anchura variada, dirección preferencial NE-SW en niveles inferiores, y NNE-SSW en superiores. Según los trabajos de (Soler, 1990) y (Soler \& Bonhomme, 1990) ; la existencia de mayor velocidad de convergencia con un ángulo de aproximadamente $45^{\circ}$ generado por el Plano de Benioff, se refleja en volúmenes de pulsaciones importantes de Magmatismo (emplazamiento del Batolito). Este aumento de velocidad de convergencia es evidenciado por el paso de cuenca volcánica marginal a Arco Insular donde el frente del Arco durante este emplazamiento se extiende hacia el Este generando un ensanchamiento.

De esta manera, la columna estratigráfica de los volcánicos-sedimentarios del Grupo Casma, está

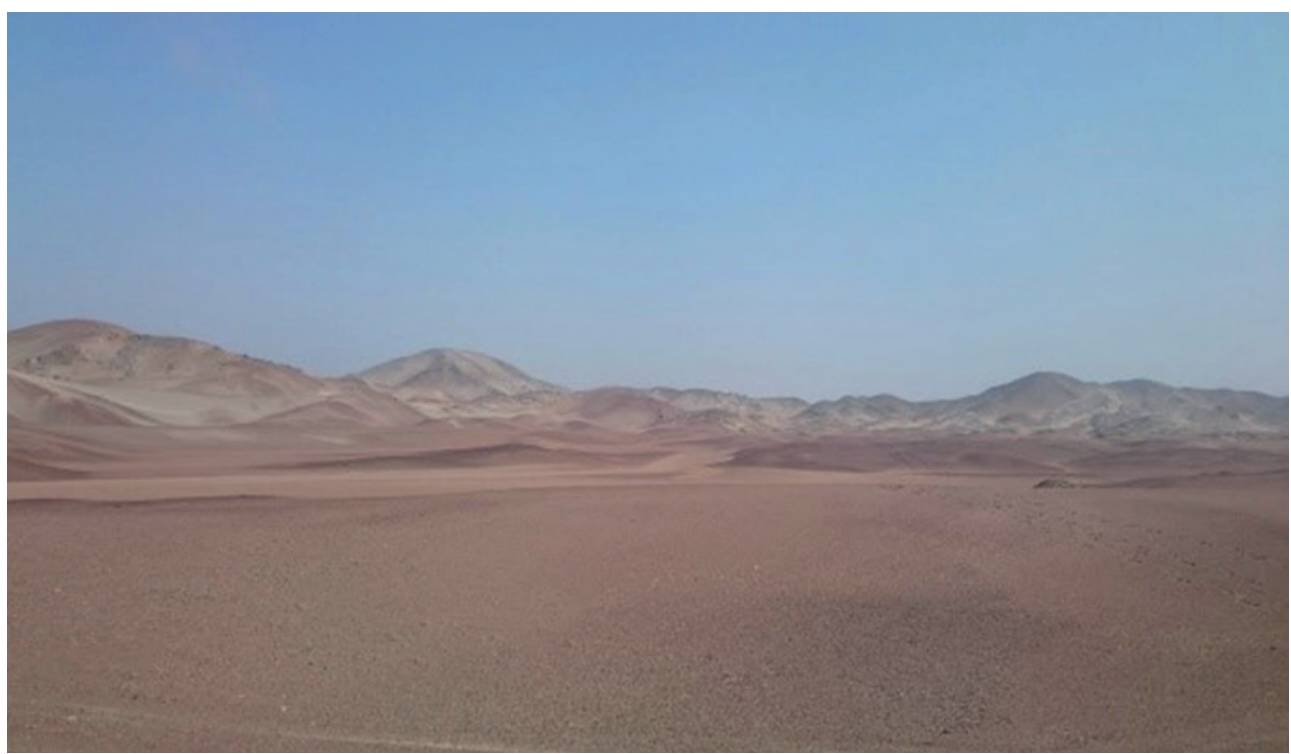

Figura 2. Se observa la coloración rojiza predominante, además la presencia de geoformas positivas en la Zona C-3 


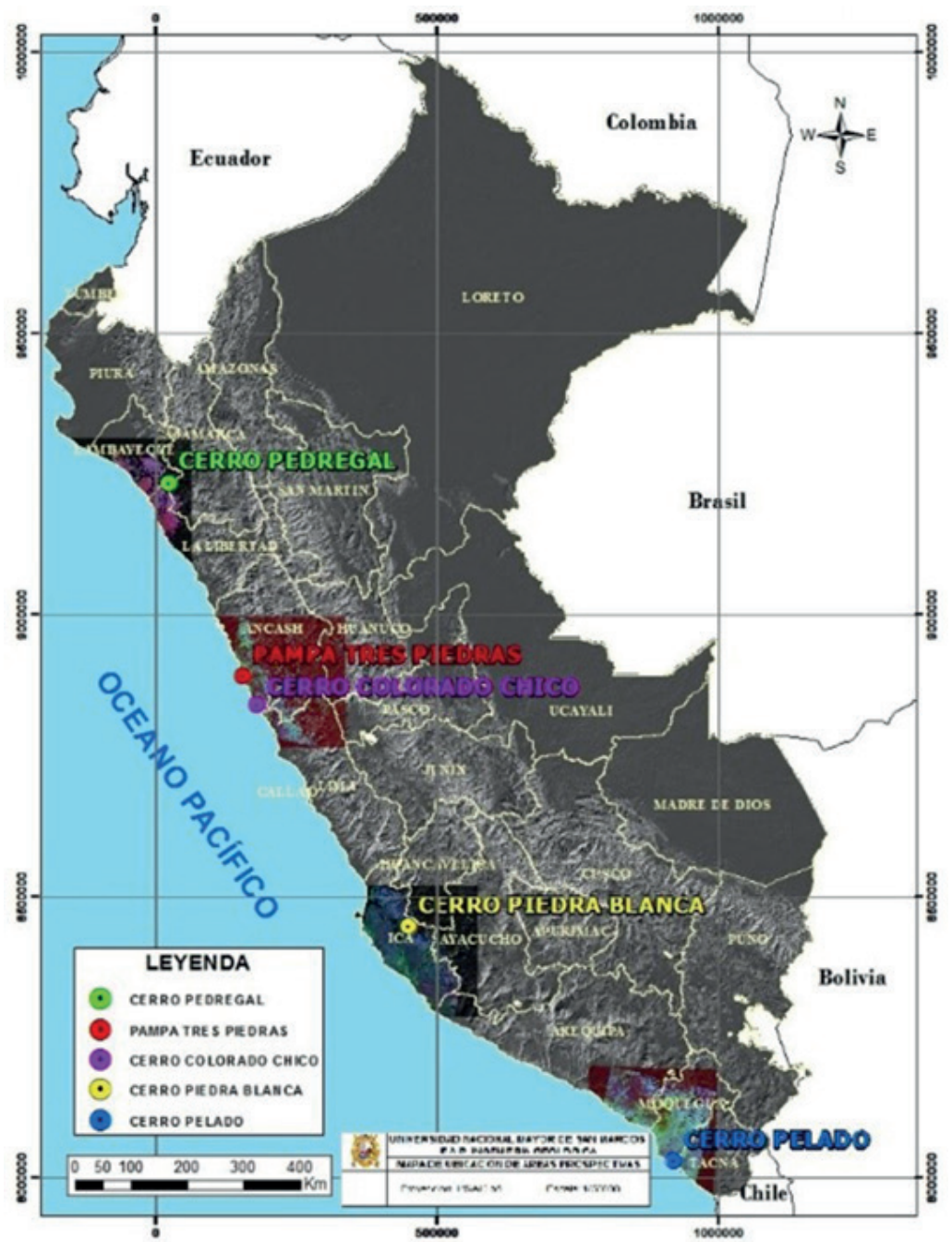

Figura 3. Mapa de ubicación de áreas prospectivas obtenidas del procesamiento de imágenes satelitales Landsat 8 con ENVI 5.3
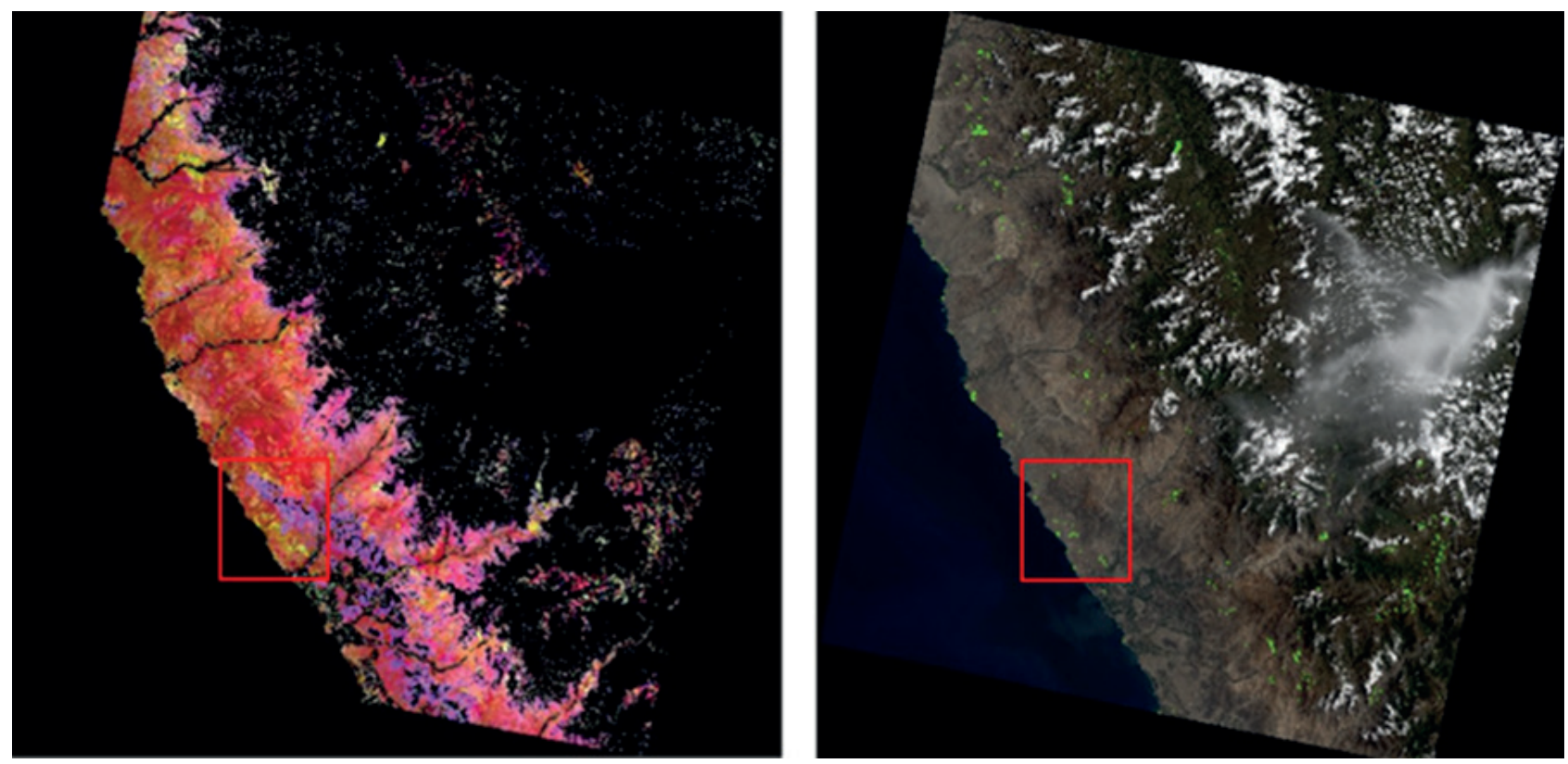

Figura 4. Imagen satelital Landsat 8, Derecha: procesada mediante la combinacion de las bandas red, near infrared (NIR), SWIR1 y SWIR2 obteniendo zonas con presencia de arcillas (tonalidad verdosa). Izquierda: Imagen con ratios de bandas ("red/blue" para óxidos y "SWIR1/SWIR2" para arcillas) obteniendo zonas con presencia de óxidos (color rojo), arcillas (color verde) y óxidos-arcillas (color amarillo) 
conformado en la base por lavas almohadilladas de la Fm. Punta Gramadal, sobreyace Fm. La Zorra de tufos andesiticos, Fm Breas de cherts, Fm Lupin con lavas andesiticas en almohadillas y piroclástico de la Fm. Pararín. Suprayace en discordancia erosiva el Grupo Calipuy y Fm. Fortaleza. Al final sobreyace los depósitos aluviales de quebrada y eólicos (Cobbing, 1973), (Guevara, C., 1980).

Regionalmente existe evidencia de 4 etapas de deformación estructural: la primera es el levantamiento de los Andes, la segunda es la Orogenia Andina que genero el plegamiento y fallamiento que afecto al Grupo Casma, la tercera que se caracteriza por fallamiento en bloques que segmenta a los Andes, y la final es el levantamiento tectónico de los Andes durante el Plioceno-Pleistoceno.

\subsection{Geología Distrital}

El área de estudio se conforma por secuencias de rocas volcánicas y volcano-sedimentarias identificadas como Grupo Casma (Cobbing, 1973) (Guevara, C., 1980) y cuerpos intrusivos subvolcánicos aparentemente pertenecientes al Batolito de la Costa (Cobbing, 1973), (Pitcher, 1977), así como numerosos cuerpos volcánicos menores (diques).

Se han identificado 5 zonas con evidente alteración hidrotermal (Figura 6). La zona C1 (182500 E - 8835000 N) y C2 (180640 E - 8837058 N) están conformadas por rocas volcánicas andesíticas (silicificadas, cloritizadas y ocasionalmente piritizadas) y brechas con halos de oxidación moderada siendo cortada por vetas de cuarzo de hasta $2 \mathrm{~m}$ de ancho (con 3 generaciones de cuarzos y sílice) con óxidos (hematita y jarosita) como patinas, algunas de las vetas poseen óxidos y sulfuros de $\mathrm{Cu}$ (ej. covelita, malaquita), también se observa venillas (1 a $5 \mathrm{~mm}$ ) de cuarzo y hematita. Existen estructuras con rumbo Andino como Andino Normal. Adicionalmente en la Zona C2 se encuentra un cuerpo pórfido dacítico hacia el Sur.
En la zona C3 (179800 E - 883770 N) también se observa una roca caja volcánica andesítica de textura afanítica a porfirítica con oxidación moderada cortada por diques de andesita porfirítica de color gris verdoso cloritizado con pirita y calcopirita diseminada, con magnetismo posiblemente por la magnetita. Hacia el Este se encuentra un cuerpo intrusivo zonificado, desde el núcleo altamente silicificado con alta cantidad de pirita y calcopirita diseminada, posteriormente disminuye la pirita y hacia la periferia se encuentran brechas silicificadas de fragmentos medianos con diseminación de pirita y menor calcopirita.

La zona C4 (178745 E - $8838320 \mathrm{~N})$ está conformado por un stock de cuarzo brechado silicificado y hacia los alrededores se observa oxidación moderada (conformada por minerales de hematita, jarosita y goethita), cortando a las rocas volcánicas andesiticas que también presentan oxidación moderada.

Por último, la zona C5 (178140 E - 8840000 N) está conformada por un stock de cuarzo que corta las rocas volcánicas andesíticas porfiríticas silicificadas y con pirita diseminada (ver Figura 5), a la vez cubiertas por un halo de oxidación. También estos son cortados por numerosos diques andesiticos sin presencia de mineralización alguna.

\section{MÉTODOS}

\subsection{Estudios Petromineralógicos}

Se realizó el estudio de 6 muestras de roca proveniente de los 5 centros de alteración, contando con 6 estudios de petrografía y 6 estudios mineragráficos con apoyo del Laboratorio de Petromineralogia de INGEMMET. Se procedió a realizar los estudios macroscópicos y posteriormente microscópicos con el fin de saber las especies mineralógicas tanto de minerales transparentes, translucidos y opacos (ver Tabla 1).

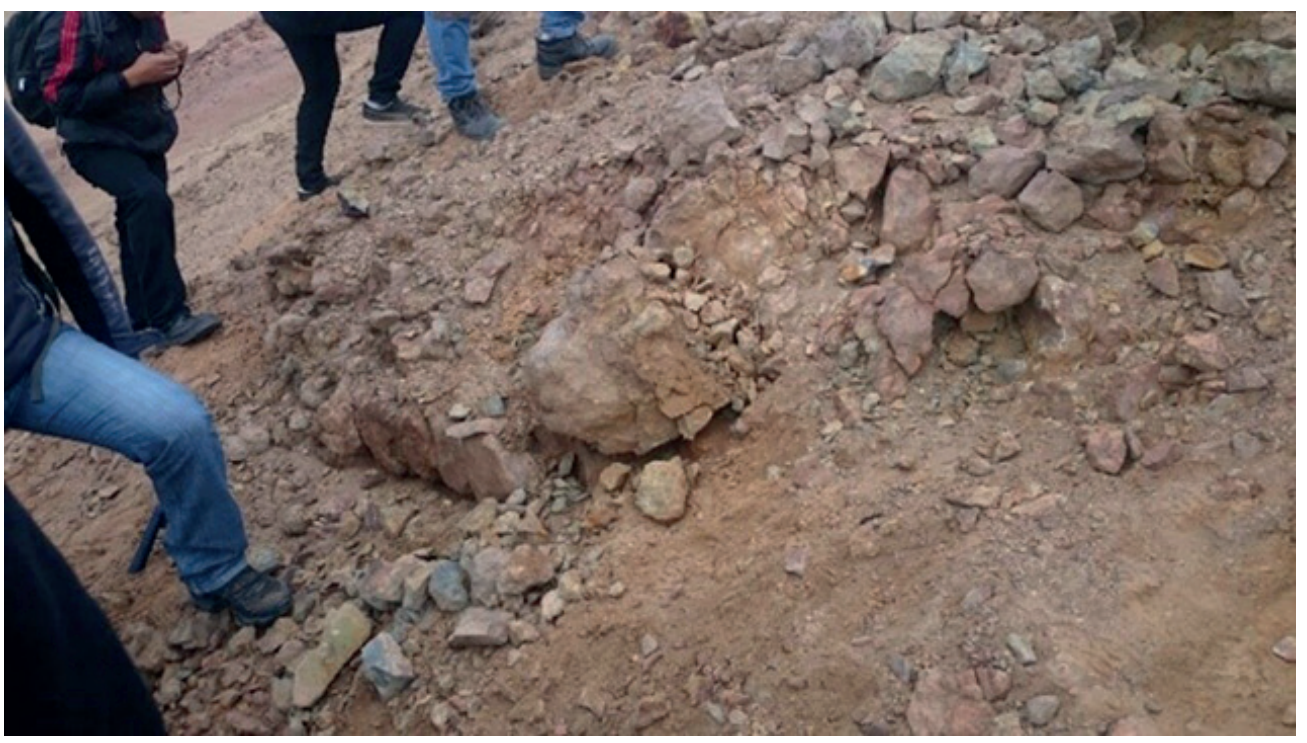

Figura. 5. Fragmentos caídos del stock de cuarzo en la Zona C-5, donde se pudo ver fuerte Silicificación además de diseminado de pirita fina 


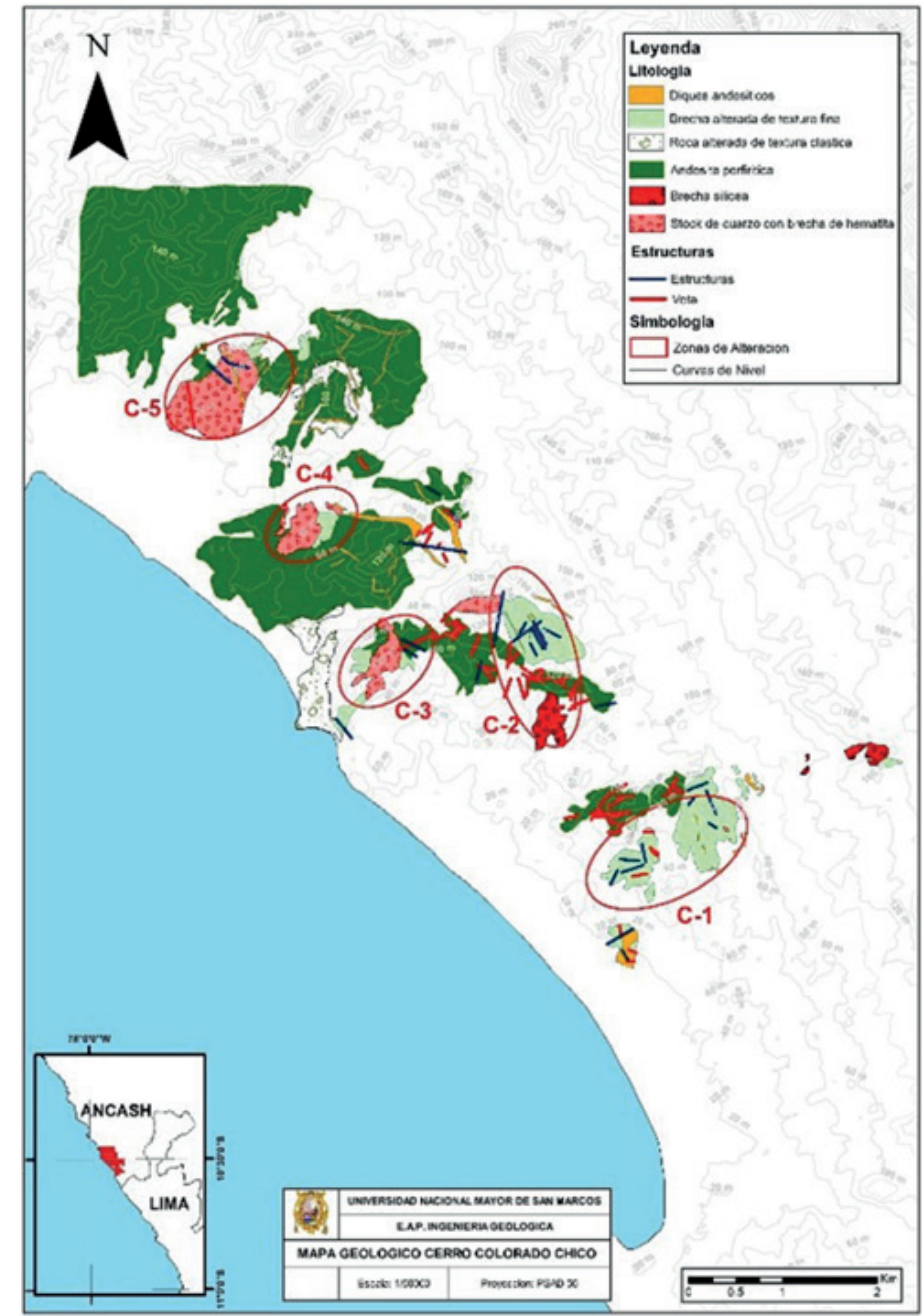

Figura 6. Mapa geológico distrital del área de estudio ubicando las 5 zonas de alteración

\subsection{Detalle de los Estudios de laboratorio}

Según los estudios realizados, los resultados obtenidos son los siguientes:

\subsubsection{Muestras $N^{\circ} 1$ (Código 58)}

Muestra de Estructura de la Zona 1. Color blanco con tonalidades pardas a rojizas, textura relíctica conformada por cuarzo hidrotermal y abundantes óxidos de hierro (goethita anhedral y botroidal), jarosita (en intersticios) y micas microfibrosas con impregnaciones de arcillas. Fuerte silicificación y débil oxidación (ver Figura 7).

\subsubsection{Muestras $N^{\circ} 2$ (Código 67)}

Muestras de Estructura de la Zona 2. Color blanco con tonalidades pardas a rojizas, textura relíctica conformada cuarzo de relleno hidrotermal con presencia de cuarzo, pirita diseminada (anhedral a subhedral en $\mathrm{GG}^{\prime}$ 's) y óxidos de hierro (hematita y goethita). Fuerte silicificación, débil oxidación, argilización y carbonatación casi incipiente (ver Figura 8).

\subsubsection{Muestras $N^{\circ} 3$ (Código 70)}

Muestras de Estructura de la Zona 2. Color blanco con tonalidades rojizas, de textura relíctica conformada por cuarzo de relleno hidrotermal, venillas de abundante óxido de hierro, además de tener impregnaciones de arcillas y zonas con mayor cantidad de sericita intersticial. Fuerte silicificación, débil oxidación y sericitación (ver Figura 9).

\subsubsection{Muestra $N^{\circ} 4$ (Código 80)}

Muestras de Roca ígnea volcánica alterada de la Zona 3. Color gris con tonalidades rojizas, de textura porfídica con arcillas, óxidos de hierro (en venillas y oquedades) inmersos en matriz silicificada y rutilo en cristales anhedrales. Alteración predominante es silicificación seguido por oxidación moderada y argilización débil (ver Figura 10).

\subsubsection{Muestra $N^{\circ} 5$ (Código 86)}

Muestra de Brecha de la Zona 4. Brecha monomíctica de color naranja pardusco con fragmentos de roca silicificada (clasto soportada) en matriz de óxidos de hierro y cuarzo, los fragmentos clásticos presentan rutilo diseminado. Además, se tiene pirita diseminada y reemplazada por goethita, pirrotita en trazas (ver Figura 11).

\subsubsection{Muestra $N^{\circ} 6$ (Código 100)}

Muestra de estructura de relleno de cuarzo y óxidos de la Zona 5. Color rojo grisáceo, con textura de relleno, minerales de 
Tabla 1. Código, ubicación y características de los resultados de las muestras utilizadas en estudios de laboratorio en INGEMMET

\begin{tabular}{cccccll}
\hline & & \multicolumn{5}{c}{ Estudios Petrográficos y Mineragráficos } \\
\hline Nro. Ingemmet & $\mathbf{N}^{\circ}$ & Norte & Este & \multicolumn{1}{c}{ Estudio Petrográfico } & \multicolumn{1}{c}{ Estudio Mineragráfico } & Mineralización \\
\hline 58 & 1 & 8835326 & 182112 & Muestras de Estructura & Pirita, hematita, jarosita y goethita & $\mathrm{hm}$, lim. \\
67 & 2 & 8836677 & 182036 & Muestras de Estructura & Pirita, hematita, jarosita y goethita & $\mathrm{hm}, \mathrm{Ox}$ 's de $\mathrm{Cu}$ \\
70 & 3 & 8837435 & 181533 & Muestras de Estructura & Pirita, hematita y goethita & Ox's de Fe y Cu \\
80 & 4 & 8836780 & 179819 & Roca Volcanica Alterada & Rutilo, goethita y limonita & Qz, cv, brn, az, hm \\
86 & 5 & 8838515 & 179200 & Brecha Hidrotermal & Pirita, pirrotita, rutilo, goethita y limonita & Lim, Cz \\
100 & 6 & 8839962 & 179123 & Estructura de Relleno de Cuarzo y Oxidos & Pirita, calcopirita, rutilo y goethita & $\mathrm{hm}, \mathrm{hoet}$ \\
\hline
\end{tabular}

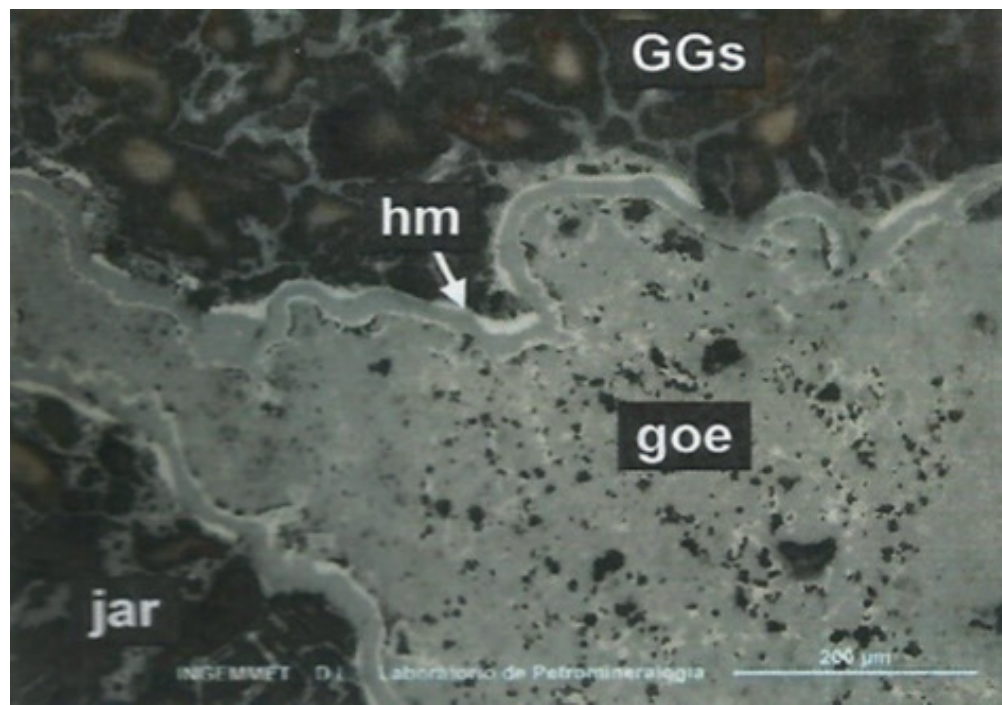

Figura 7. Fotomicrografía de sección pulida donde se aprecia los minerales como goethita con bordes de hematita

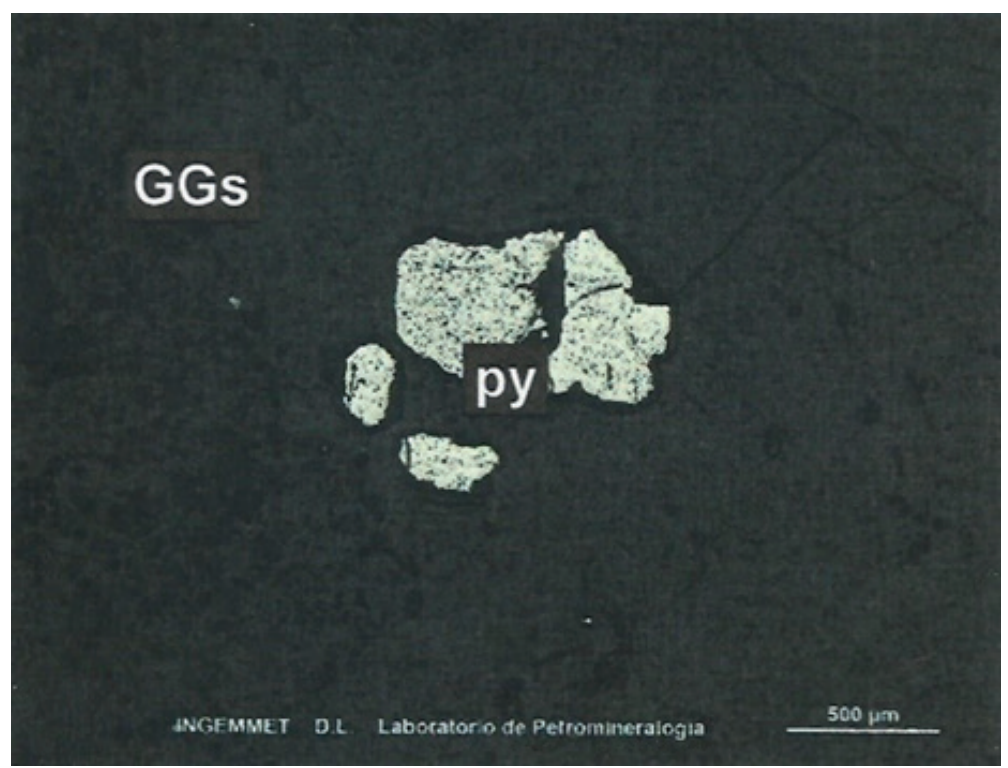

Figura 8. Fotomicrografía de sección pulida donde se aprecia pirita diseminada en gangas 


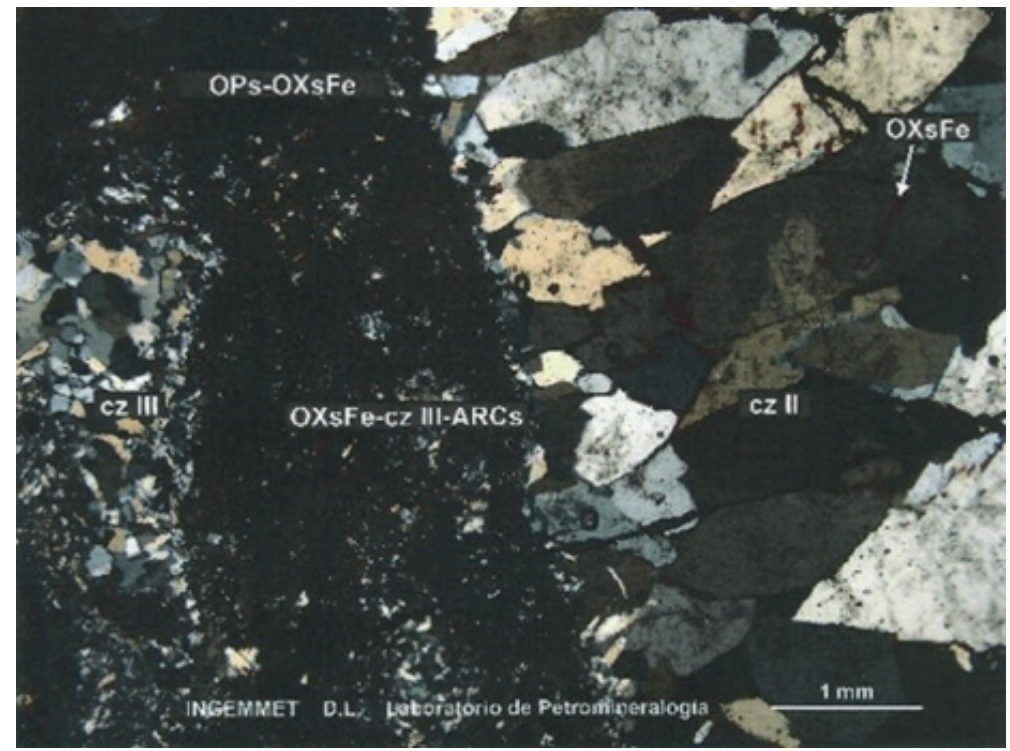

Figura 9. Fotomicrografía de lámina delgada diferentes tipos de cuarzo, arcillas y óxidos de hierro

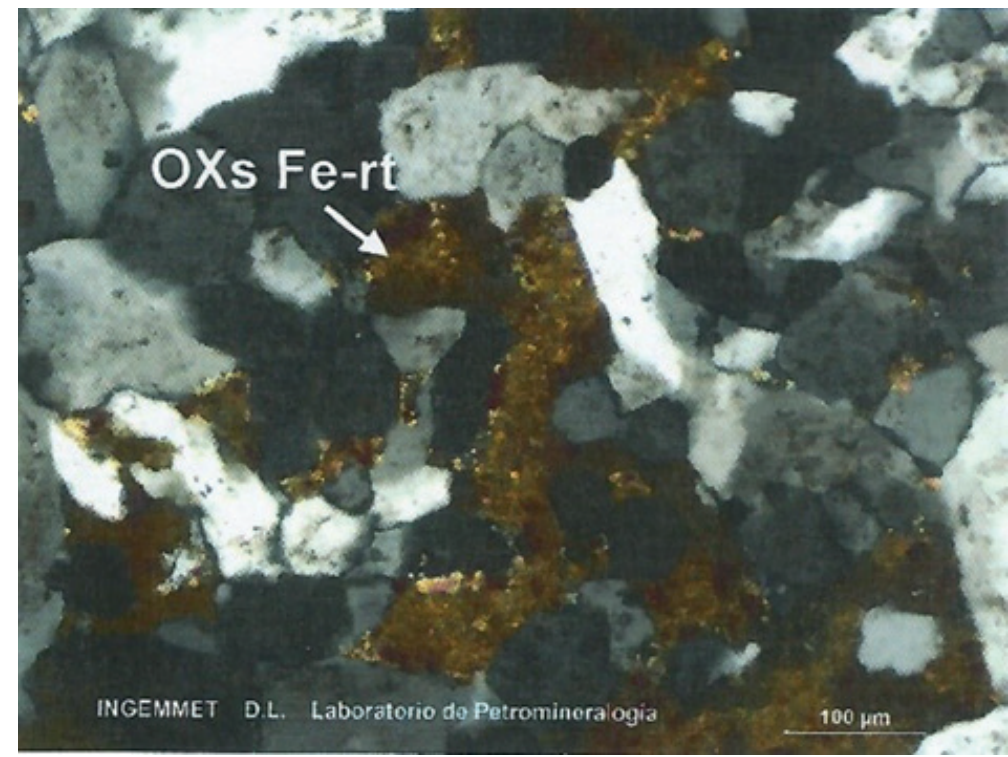

Figura 10. Fotomicrografía de lámina delgada (izquierda) y sección pulida (derecha) donde se aprecia los minerales como rutilo y óxidos de hierro

óxidos de hierro (goethita y hematita), algunos parches de micas, y además cristales de rutilo subhedrales de manera de trazas en moldes de cristales, escasos cristales de pirita y calcopirita diseminada. Alteración predominante es silicificación seguido por oxidación moderada (ver Figura 12).

\section{RESULTADOS}

Dadas las evidencias encontradas con los estudios geológicos y petromineralógicos, en el área de Cerro Colorado Chico, proponemos a esta como un yacimiento tipo IOCG.

Las características esenciales a estructuras verticales y/o subverticales dentro de un control de cizalla de orientación andina. Este control dado en el Cretáceo superior se relaciona con un periodo de extensión durante la subducción evidenciado por generar un vulcanismo bimodal (Cueva, E., Mamani, M., Rodríguez, R., s.f.). Este vulcanismo (representado por el Grupo Casma; (Guevara, $C ., 1980$ ) datado en $130-105 \mathrm{Ma}$, corresponde a la época con mayor presencia de yacimientos tipo IOCG Mesozoicos en el Sur del Perú y Norte de Chile (Chen et al., 2013).

\section{DISCUSION}

En el caso de las brechas silíceas sin mucha mineralización evidente, encontradas en la Zona C-2, se podría tener la presencia de un posible Quartz Pod (Lobo-Guerrero, s.f.), 


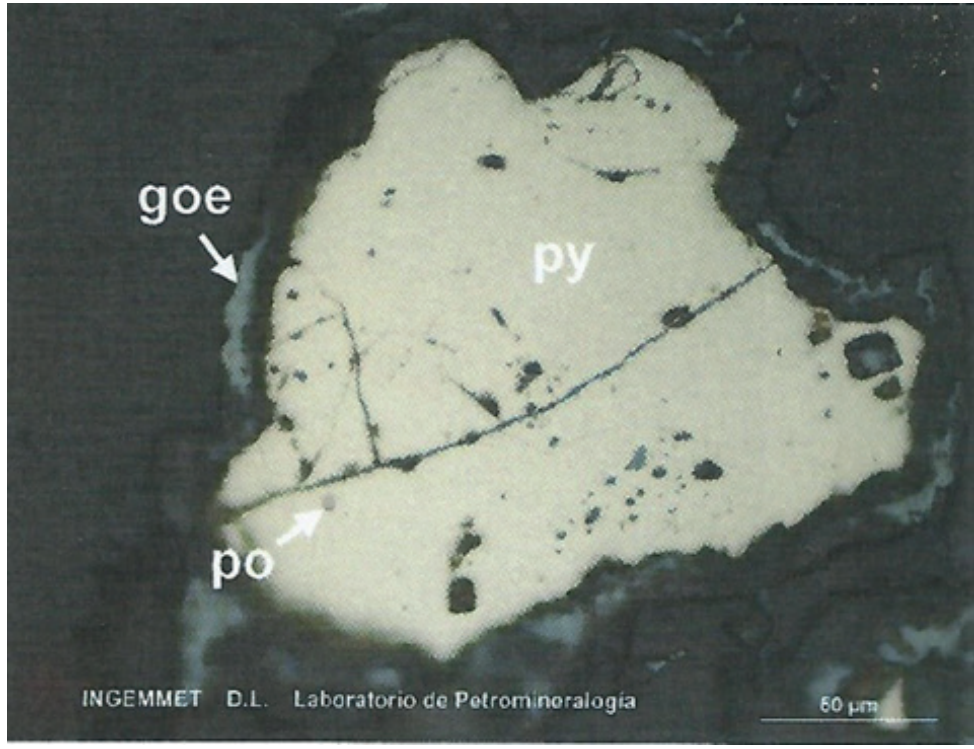

Figura 11. Fotomicrografía de sección pulida donde se aprecia los minerales como rutilo, pirita y trazas de pirrotita

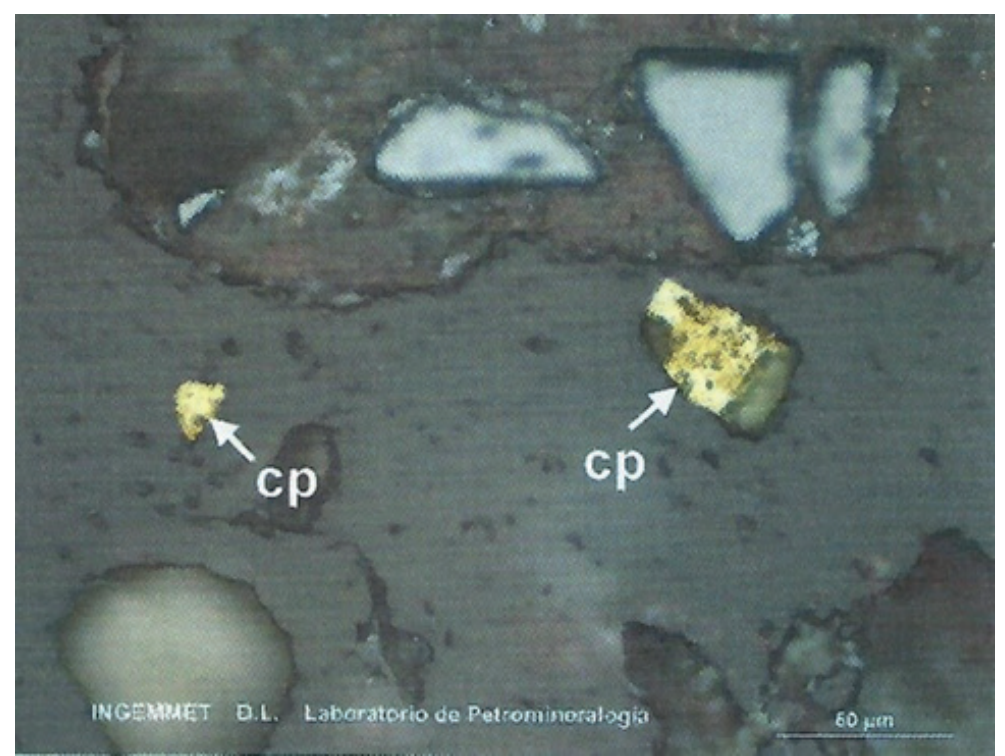

Figura 12. Fotomicrografía de sección pulida donde se aprecia diseminados de calcopirita

cuerpos estériles ligados a los plutones intrusivos que aún siguen en estudio, aunque se tiene evidencia de estos en otros proyectos en Ancash (Biminchumo Sagástegui, 2013). Otro indicador podría ser la presencia de la gran cantidad de diques andesíticos subverticales (presencia mantélica (Sillitoe, 2003).

La presencia de poca magnetita y gran cantidad de hematita-goethita nos podría indicar: alteración supergena, dando la posible presencia de magnetita en profundidad (Barton \& Johnson, 2004), (Richards \& Mumin, 2013). También se pudo evidenciar la presencia de un gran halo de alteración cuarzo-hematita-sericita-clorita que nos indicaría la parte más superficial y de menor temperatura del yacimiento tipo IOCG (Hitzman et al., 1992), (Tornos et al., 2008) siendo necesario hacer más estudios para determinar su potencial en profundidad.

\section{CONCLUSIONES}

- La teledeteccion es una herramienta indispensable para poder localizar zonas prospectables de yacimientos tipo IOCG, usando las imágenes Landsat 8 en el software ENVI 5.3 con el metodo de ratio de bandas, nos proporciono zonas con presencia de óxidos, arcillas y óxidos-arcillas para su respectiva verificación de campo en el area denominada Cerro Colorado Chico, quedan pendientes otras áraes similares a explorar y confirmar. 
- Los afloramientos relacionados con cuerpos intrusivos a subvolcánicos del Batolito de la Costa que intruyen al Grupo Casma volcánico sedimentario, se relacionan con geoformas positivas a modo de cerros aislados con coloración rojiza a verdosa, originando una intensa anomalía de color tanto en los afloramientos como en los suelos de variada tipología.

- El factor estructural ha sido muy importante de definir, ya que nos permitió reconocer un fallamiento regional de tendencia andina $\mathrm{N} 340^{\circ}$, paralela a la costa que se intersecta con fallas antiandinas $\mathrm{N} 40^{\circ}$ - N50 $0^{\circ}$ en cuyo compartimento se desarrolla el proyecto.

- En cuanto a las zonas de alteración, los volcánicos sedimentarios del Grupo Casma se encuentran silicificados con pirita y presencia de óxidos de hierro, alteración sericita-clorita, un ensamble de minerales de alteración característico de zonas superficiales de yacimientos tipo IOCG. Los cuerpos intrusivos silíceos que cortan al Grupo Casma, se encuentran con alteración hidrotermal, pero sin mineralización, lo que podrían ser evidencia de Quartz Pods (Lobo-Guerrero, s.f.) mencionados anteriormente en el Norte (Biminchumo, 2013).

- En los estudios de petromineralogía de las 6 muestras, se observa la presencia de óxidos de hierro (hematita y goethita) abundantes, así como jarosita y limonita. También podemos corroborar las alteraciones predominantes (silicificación y oxidación) así como la sericitación débil, aunque también existen agregados micáceos en intersticios que podrían ser sericita, y por último, la incipiente argilización y carbonatación. Existe además rutilo (oxido de titanio), sericitación, y gran contenido de óxidos de hierro (hematita en bordes de goethita, sin o con bajo contenido de titanio), siendo indicadores de partes altas de yacimientos tipo IOCG.

\section{AGRADECIMIENTOS}

Agradecemos el apoyo brindado por las autoridades de la E.A.P. de Ingeniería Geológica de la UNMSM. Al INGEMMET, en especial al equipo de trabajo en los laboratorios de teledetección y microscopia. Además, un especial agradecimiento al Ing. Luis Vargas por sus comentarios, sugerencias y correcciones, al $\mathrm{Mg}$. Hugo Rivera por sus consejos. En la etapa de campo, al técnico Raymundo Leguía y a los estudiantes Sebastián Loayza, Gustavo Miranda y Yuder Espíritu quienes colaboraron activamente en el campo y gabinete.

\section{BIBLIOGRAFÍA}

Barton, M. D., \& Johnson, D. A. (2004). Footprints of Fe-oxide($\mathrm{Cu}-\mathrm{Au}$ ) systems. University of Arizona, 6.

Biminchumo Sagástegui. (2013). Análisis geológico del cuerpo de cuarzo Pod Caseli del IOCG DIVIMIN, usando como herramientas magnetometría, espectrometría y polarización inducida Ancash, Lima-Perú. Universidad Nacional de Ingeniería. http://cybertesis.uni.edu.pe/handle/uni/10973

Chen, H., Cooke, D. R., \& Baker, M. J. (2013). Mesozoic Iron Oxide Copper-Gold Mineralization in the Central Andes and the Gondwana Supercontinent Breakup. Economic Geology, 108(1), 37-44. https://doi.org/10.2113/econgeo.108.1.37

Cobbing, E. J. (1973). Geología de los cuadrángulos de Barranca, Ámbar, Oyón, Huacho, Huaral y Canta 22-h, 22-i, 22-j, 23h, 23-i, 23-j-[Boletín A 26]. Instituto Geológico, Minero y Metalúrgico - INGEMMET. https://repositorio.ingemmet. gob.pe/handle/20.500.12544/144

Cobbing, E. J., \& Pitcher, W. S. (1979). El Batolito costero en la parte central del Perú-[Boletín D 7]. Instituto Geológico, Minero y Metalúrgico - INGEMMET. https://repositorio. ingemmet.gob.pe/handle/20.500.12544/326

Cueva, E., Mamani, M., Rodríguez, R. (s.f.). calameo.com. Recuperado 8 de junio de 2020, de https://www.calameo. $\mathrm{com} / \mathrm{read} / 000820129 \mathrm{c} 885 \mathrm{f} 42 \mathrm{~d} 7376$

Guevara, C. (1980). https://www.sgp.org.pe/category/ bibliovirtual/?result $=4101$

Hitzman, M. W., Oreskes, N., \& Einaudi, M. T. (1992). Geological characteristics and tectonic setting of proterozoic iron oxide (Cu-U-Au-REE) deposits. Precambrian Research, 58(1), 241-287. https://doi.org/10.1016/0301-9268(92)90121-4

Jacay, J, \& Sempéré, T. (2005). Emplacement levels of the coastal batholith in central Peru. 3.

Jacay, Javier. (2005). ANÁLISIS DE LA SEDIMENTACIÓN DEL SISTEMA CRETÁCEO DE LOS ANDES DEL PERÚ CENTRAL. Revista del Instituto de Investigación de la Facultad de Ingeniería Geológica, Minera, Metalúrgica y Geográfica, 8(15), 49-59.

Lobo-Guerrero. (s.f.). Scribd. Recuperado 8 de junio de 2020, de https://www.scribd.com/document/328787622/4-QuartzPods-2004-2p

Mamani et al. (2010). calameo.com. https://www.calameo.com/ $\mathrm{read} / 000820129 \mathrm{ef} 865408 \mathrm{c} 3 \mathrm{e} 8$

Mamani Huisa, M. I., Rodríguez Mejía, R., Acosta Pereira, H., Jaimes Salcedo, F., Navarro Colque, P. A., \& Carlotto Caillaux, V. S. (2012). Características litológicas y geoquímicas mas resaltantes de los arcos magmáticos del Perú desde el Ordovícico [Artículo presentado en Congreso]. Instituto Geológico, Minero y Metalúrgico - INGEMMET. https://repositorio.ingemmet.gob.pe/ handle/20.500.12544/741

Richards, J. P., \& Mumin, A. H. (2013). Magmatic-hydrothermal processes within an evolving Earth: Iron oxide-copper-gold and porphyry $\mathrm{Cu} \pm \mathrm{Mo} \pm \mathrm{Au}$ deposits. Geology, 41(7), 767770. https://doi.org/10.1130/G34275.1

Sillitoe, R. H. (2003). Iron oxide-copper-gold deposits: An Andean view. Mineralium Deposita, 38(7), 787-812. https:// doi.org/10.1007/s00126-003-0379-7

Soler, P. (1990). Cronologia y distribucion espacial del magmatismo en el Peru central durante el cretacico superior y el cenozoico-Relaciones con las modalidades 
de la subduccion de la plaza Nazca (Farallon) debajo del continente sud-americano. Boletin de la Sociedad Geologica del Peru, 81, 81-86.

Soler, P., \& Bonhomme, M. G. (1990). Relation of magmatic activity to plate dynamics in central Peru from Late Cretaceous to present. En Geological Society of America Special Papers (Vol. 241, pp. 173-192). Geological Society of America. https://doi.org/10.1130/SPE241-p173
Tornos, F., Carriedo, J., Velasco Roldán, F., \& Tomé, C. (2008, enero 1). La génesis de los depósitos de tipo IOCG: Geología y geoquímica de mineralizaciones en los Andes e Iberia. https://www.researchgate.net/publication/233801893_La_ genesis de los depositos de tipo IOCG Geologia y geoquimica_de_mineralizaciones_en_los_Añdes_e_Iberia 
